\title{
“ME CANSO DE SER HOMBRE" Paternidad periférica en el trabajo minero chileno
}

\author{
Jimena Silva \\ Escuela de Psicología, Facultad de Humanidades, Universidad Católica del Norte, Antofagasta, \\ Chile \\ Paulina Salinas \\ Académica Escuela de Periodismo, Facultad de Humanidades, Universidad Católica del Norte, \\ Antofagasta, Chile
}

Resumen En este artículo se analizan los significados del ser padre trabajador bajo sistemas de turno en la industria minera. Se realizaron entrevistas. Concluimos que estos hombres, al igual que otros trabajadores latinoamericanos, comparten el malestar entre el modelo de masculinidad / cabeza de familia versus responder a las demandas sociales. Se observa que los símbolos con poder de mandatos fijos e incuestionables, han quedado desnudos en la relación padre-hijo, mostrando su resquebrajamiento. Cambios que desvalorizan y desacreditan la figura del padre en la escena familiar, acentuada con las altas exigencias de flexibilidad laboral minera.

Palabras-clave: paternidad, trabajo, minería, sistema de turnos.

“Estou cansado de ser homem": paternidade periférica no trabalho de mineração no Chile

Resumo Neste artigo analisam-se os significados de ser pai trabalhador em sistemas de turno na indústria da mineração. A partir de entrevistas, concluiu-se que estes homens, tal como outros trabalhadores latino-americanos, compartilham o desconforto entre o modelo de masculinidade / chefe de família versus responder às demandas sociais. Observa-se que os símbolos com mandatos fixos e inquestionáveis têm ficado a nu na relação pai-filho mostrando a sua rutura. Mudanças que desvalorizam e desacreditam a figura do pai no cenário familiar acentuam-se com as altas exigências de flexibilidade do trabalho na mineração.

Palavras-chave: paternidade, trabalho, mineração, sistema de turnos.

"I'm tired of being a man": peripheral paternity in Chilean mining work

Abstract In this article we analyzed the implications of being a father who works shifts in the mining industry. Through interviews we concluded that these men, like other Latin American workers, share the uneasiness between the masculinity / head of household model and the responsibilities of responding to social demands. It was observed that the traditional symbols of power and unquestionable patriarchal authority have been unattended to in the father-son relationship, causing fracturing of said paradigm. Changes that devalue and discredit the father figure in family dynamics are accentuated by the high demands of the mining work schedule.

Keywords: paternity, work, mining, shift system.

"Je suis fatigué d'être un homme": paternité périphérique dans le travail minier chilien

Résumé Cet article traite de la signification d'être père et de travailler en système de travail posté dans l'industrie minière. Des entrevues ont été menées. Nous concluons que ces hommes, comme d'autres travailleurs latino-américains, partagent le malaise entre le modèle de la masculinité / chef de famille, par rapport aux demandes sociales. On observe que les symboles ayant des mandats fixes de puissance sont remis en question et mis à nu dans la relation père-fils montrant leur rupture. Les changements qui dévalorisent et discréditent la figure du père s'accentuent avec les exigences de la flexibilité du travail dans les mines.

Mots-clés: le rôle parental, le travail, l'exploitation minière, le système de travail posté. 


\section{Introducción}

A nivel internacional, en la industria minera la conciliación entre trabajo y familia ha sido una de las tensiones extremas que ha provocado desbalances en los vínculos padre-hijo(a), acentuando su lugar como proveedor económico al interior del hogar y productivo en la sociedad (Pini y Mayes, 2012; Hubbard, 1999; Jackson, 1996). En este rubro las exigencias laborales propias de una industria globalizada y competitiva tiende a legitimar un estilo de paternidad periférica y ausente (Valdés, 2009; Pavés y Hernández, 2014). ${ }^{1}$

De acuerdo a los antecedentes disponibles, los trabajadores mineros chilenos establecen sus prioridades, enmarcan sus decisiones y expresan satisfacción o no en función del status y prestigio en el trabajo; a pesar que se encuentran sometidos a sistemas de turno, largas jornadas, condiciones de riesgo, altura, temperaturas extremas, alteraciones en el ritmo de sueño, ocio e intimidad familiar (Pavés y Hernández, 2014; Silva y Barrientos, 2008; Olavarría, 2000).

La legitimidad de estos regímenes laborales en la cultura organizacional de la industria minera se encuentra ampliamente reconocida, no sólo en Chile sino a nivel internacional, inclusive han sido asumidos como modelos para otras faenas (ferrocarriles, empresas marítimas, instituciones militares, entre otras). De este modo, el trabajador se adapta a una amplia gama de sistemas de turnos en los cuales, por una parte, se aleja de la vida doméstica, de las tareas del cuidado y crianza de los(as) hijos(as), y por otra, se intensifican las relaciones androcéntricas con sus compañeros, donde predominan prácticas, discursos y escenarios masculinizados (Salinas, Barrientos y Rojas, 2012; Salinas y Romaní, 2016).

La industria mantiene un sistema histórico-cultural androcentrado para los hombres, que implica una construcción privilegiada de la condición masculina, que tiene como eje ser el proveedor principal y la autoridad que éste genera, ligado al trabajo fuera del hogar, a la autonomía en las decisiones y al poder del padre en la familia. No obstante, en la actualidad esta estructura laboral que fue hegemónica en la sociedad industrial, se cuestiona frente a las transformaciones que experimentan los individuos y sus familias, donde las culturas globalizadas, demandan mayor calidad de vida, inclusive en la industria minera (Meller, 2013; March, Van Dijk y Hernández, 2015).

Los turnos ${ }^{2}$ configuran una tensión entre trabajo y familia en diversos grados dada la distancia de los asentamientos mineros en relación al lugar de residencia, el ciclo de vida de la pareja e hijos(as), la edad del trabajador y la mujer, los ciclos migratorios internos asociados, entre otros (Pini y Mayes, 2012; Pini, Mayes y Boyer, 2013; Ward, 2015). A lo anterior, se suma una sobrecarga de responsabilidades en la pareja del trabajador, agudizando la polaridad público/privado en la vida cotidiana, mientras el hombre en la mina trabaja en horarios excepcionales de acuerdo a las exigencias de producción. En esta modalidad de interacción, las mujeres experimentan conflictos de poder, por el estilo de paternidad "acordeón" o "fly-in fly-out" que implica un flujo

Este artículo forma parte de hallazgos de proyectos Fondecyt N.$^{\circ} 1180079$ y Fondecyt N.$^{\circ} 1180016$. Días trabajados por días de descanso: $4 \times 4,4 \times 3,5 \times 3,8 \times 6,5 \times 5,6 \times 4,8 \times 8,9 \times 7,10 \times 10,15 \times 15$. 
de presencias-ausencias del hombre en el hogar, lo que ha sido ampliamente investigado en la minería australiana (Pini y Mayes, 2012), en la inglesa (Ward, 2015), y en menos proporción en la minería latinoamericana.

En base a estos antecedentes, buscamos comprender los significados del ser padre trabajador bajo sistemas de turno; para ello, buscamos responder ¿cómo significan actualmente la paternidad los trabajadores mineros, en un mercado laboral que exacerba su rol productivo-proveedor, frente a un sistema familiar que demanda más compromiso y cuidado de los(as) hijos(as)?; ¿cómo enfrentan la dicotomía entre paternidad-familia y trabajo?

\section{Paternidad en la minería}

En la actualidad, la construcción simbólica de la identidad masculina y la subjetividad de los hombres son centrales en los estudios de género, en la medida en que se enfocan en las vicisitudes socioculturales y psicológicas atribuidas a la significación del ser varón. Aunque existe una gran diversidad de identidades masculinas, predominan los dispositivos hegemónicos de poder que operan sobre el sujeto. Según Núñez (2016), entender los significados de la "la hombría" y "las masculinidades" significa analizarlas en sus particularidades. Una de estas expresiones se desarrolla con la paternidad, la que se ha distanciado del modelo de familia nuclear y/o extendida que caracterizó a la sociedad industrial del siglo XX, como consecuencia del ingreso masivo de las mujeres al mercado laboral. Así mismo, en los análisis se ha tomado en cuenta la flexibilidad laboral, los cambios tecnológicos de la producción y la organización del trabajo, que impone el actual sistema productivo globalizado, que no necesariamente beneficia la conciliación del trabajo con la familia, favoreciendo contrariamente los patrones de división sexual del trabajo y reforzando la paternidad periférica.

La paternidad periférica y sus dimensiones han sido investigadas por distintos(as) autores(as) que articulan trabajo y/o familia (Araujo y Martuccelli, 2012; Gray, 2010; Valdés, 2007); en ellos se destacan el estancamiento del proceso de nuclearización a través del crecimiento del porcentaje de familias monoparentales con jefatura femenina. En el caso de Chile se registra un 39\%, según la última Encuesta de Caracterización Socioeconómica (Casen, 2013). Además ha crecido la informalización del lazo conyugal-matrimonial, las familias monoparentales, las tasas de separaciones y divorcios, y los nacimientos fuera del matrimonio (Casen, 2013; Valdés, 2007; Sheng, 2013). Así mismo, la intensificación del trabajo y el lugar que éste ocupa en la vida de los sujetos.

En Chile, al igual que en otros países latinoamericanos las políticas públicas para revertir esta situación han sido insuficientes (Araujo y Martuccelli, 2012; Batthyany, 2009; Cepal, 2011; Lindberg, Kost y Maddow-Zimet, 2017). Un mayor equilibrio entre el trabajo y la familia derivaría de los esfuerzos mancomunados entre el sector público y privado que promuevan transformaciones efectivas en las prácticas laborales, la educación con perspectiva de género y las creencias socioculturales de la vida cotidiana; así los padres podrían asumir mayor responsabilidad y a la vez, 
resguardar el compromiso laboral (Abarca y Errázuriz, 2007; Leiva y Comelin, 2015). Aunque, tanto en Chile como en Latinoamérica, se observan transformaciones culturales que han renovado la paternidad material y simbólica con la des-institucionalización de la familia, principalmente de hombres jóvenes con sus hijos e hijas. Las mujeres han fortalecido sus derechos en el mercado de trabajo y se ha reconocido una mayor diversidad en la conformación familiar, contribuyendo, en algunos casos, en el compromiso de los padres con la crianza y el cuidado (Castelain-Meunier, 2005; Valdés, 2009).

En los casos de trabajadores jóvenes estudiados en Inglaterra, se observa que no solo están encasillados a mostrar formas de masculinidades, sino que éstas se expresan de formas distintas y como trabajadores adoptan múltiples identidades, de acuerdo a las exigencias del contexto. Sin embargo, es un proceso complejo (Ward, 2015), principalmente en culturas donde coexisten, por una parte, mandatos de género conservadores $\mathrm{y}$, por otra, de mayor equidad, generando desgastes psicofísicos en el proceso de compatibilización, entre hombres, mujeres, trabajo y crianza.

Un ejemplo de ello es la industria minera a nivel mundial, donde el ejercicio de la paternidad se mantiene distante de estas transformaciones culturales, debilitando el vínculo entre los miembros de la familia. Como en otros rubros de la economía, en la minería altamente globalizada, predomina el trinomio trabajo-eficiencia-productividad, dada la naturaleza ininterrumpida de la labor extractiva, lo que genera un énfasis en la individualización de los trabajadores, centrados en sus emociones y sobre demandados por la industria.

\section{Paternidad y sus diversas caras}

Respecto de la paternidad minera, en parejas jóvenes con hijos pequeños, se ejerce como un acordeón, con jornadas de trabajo intensivo y de descanso exclusivo, que desequilibran los procesos de apego y participación en la crianza. En estos casos, la madre está muy presente; en cambio los padres son distantes o de "entrada y salida" (Salinas et al., 2010; Carrasco y Vega, 2011; Silva y Barrientos, 2008). De este modo, las ausencias paternas en fechas relevantes para los hijos crean conflictos en la vida familiar. Se producen desencuentros afectivos que se "compensan" con los beneficios econó$\operatorname{micos}^{3}$ que ofrecen las compañías a sus trabajadores (altas remuneraciones, bonos, prestaciones escolares y previsionales, entre otros) (Pavéz y Hernández, 2014).

Existe un amplio acuerdo respecto a la crítica que se hace a los elementos centrales de la masculinidad hegemónica, en torno a una heterosexualidad encasillada en una escasa conexión con las emociones, exacerbando el vínculo con el estatus de

3 La Región de Antofagasta es la capital minera de Chile y se ubica en el extremo norte del país. En promedio, 48.318 personas trabajan en la minería recibiendo los sueldos más altos de la economía nacional. El ingreso promedio de una familia es de US\$ 1314 (Casen, 2013). Por ejemplo, si a nivel del país la canasta familiar cuesta US\$ 61,59, en Antofagasta alcanza US\$ 78 (Secretaría Regional de Minería, 2015). 
proveedor económico del grupo familiar (Connell, 2005; Kaufman, 1993; Olavarría, 2000). De acuerdo a Aguayo y Nascimiento (2016), la paternidad y la escasa participación de los padres en el cuidado, la crianza y las tareas domésticas, han recibido cada vez más atención (Figueroa, Jiménez y Tena, 2006; Fuller, 2000; Olavarría, 2000; Wainerman, 2007). Se ha avanzado en conocer cómo se organiza la carga de cuidado entre hombres y mujeres, y en entender cómo el trabajo remunerado y el género inciden, y marcan, dicha distribución.

Además se encuentra cuestionado este modelo cultural, por no responder a la diversidad en que se desarrollan las identidades masculina y femenina actuales. En los estudios de Valdés (2009), se encuentran representaciones sobre la figura del padre amo y maestro, que detentaba el poder y la autoridad en el pasado, así como el padre ausente y el periférico; éstas figuras son cuestionadas en las familias contemporáneas. En cambio, se encuentran rasgos de diferentes paternidades: ausentes, presentes, abdicantes, huidizos, responsables, irresponsables, desinteresados, modernos, tradicionales, entre otros.

Es sabido, que así como las construcciones de género que circulan en los sistemas sociales dificultan el derecho de las mujeres a la educación y al trabajo, o el cuidado de la salud integral, a los hombres se les dificulta y obstruyen también (con los sistemas laborales) el cuidado de su salud y lo que podríamos denominar "la salud paterna", en un sentido más integral. Figueroa (2014) destaca la búsqueda de equilibrio entre las diferentes opciones que ofrece la experiencia de la paternidad, además señala que sobre las tensiones de género "no se trata de victimizar a hombres o mujeres, divididos binariamente como recurso analítico y discursivo", pero sí de evidenciar que ambos pueden ser sujetos necesitados de protección de derechos (Figueroa, 2014).

Desde este enfoque, nos interesa destacar el elemento "tiempo en la familia", que condiciona, entre otras dimensiones, el grado de involucramiento de los hombres con el cuidado de su núcleo.

Sobre la noción del cuidado en la perspectiva masculina, aún se mantienen argumentos que distinguen los mandatos de protección ante los riesgos; así las nociones de cuidar y proteger deben ser comprendidas con diferentes implicancias en cuanto a la continuidad en el tiempo y a los comportamientos asociados a hombres y mujeres. Por ejemplo, se protege frente a un peligro inminente o coyuntural. En cambio, las labores del cuidado se desarrollan en la vida cotidiana (doméstica) en forma rutinaria. Finalmente, se educa a los hombres en los modelos de género para proveer y proteger a los hijos e hijas y a la pareja, como forma de probar su hombría desde su lugar en el mundo público. En cuanto a las mujeres, se les atribuye el cuidado cotidiano preferentemente en el mundo privado (Flores y Tena, 2014).

\section{Diseño metodológico}

Utilizamos un diseño cualitativo, basado en entrevistas realizadas entre abril 2015 y abril 2016 abordando las siguientes dimensiones: significados de ser padre y trabajador, relaciones familiares con la pareja y los(as) hijos(as), tensiones de la vida cotidiana y resolución de conflictos. Cada entrevistado firmó un consentimiento y 
autorizó el uso de la información para fines investigativos. Los criterios de inclusión fueron: (a) ser trabajador minero, (b) estar sujeto a sistema de turnos y (c) tener pareja e hijos(as), propios o no. Para el acceso a los participantes se recurrió a las redes institucionales de empresas y sus sindicatos. Utilizamos el contacto a través de "bola nieve" entre los participantes, ya que esta población es de difícil acceso por los sistemas de turnos. Participaron 22 trabajadores entre 21 y 65 años adscritos a sindicatos y seleccionados en el contexto laboral de las empresas mineras de las comunas de Antofagasta y Calama en el norte de Chile. La mayor edad de los entrevistados permitió conocer relatos de vida más extensos. La edad de los(as) hijos(as) fluctúo entre de dos y 25 años. Los niveles educativos se distribuyeron en siete trabajadores con educación superior y postgrado, situados en áreas administrativas y de gerencia; cuatro con educación superior del área de prevención y profesional; siete con educación media y especialización de operaciones y manejo de maquinaria pesada y cuatro con educación media incompleta de mantención, abastecimiento y limpieza.

\section{Análisis de los datos}

Se utilizó un procedimiento inspirado en distintos aportes para captar la diversidad de experiencias y puntos de vista expresados en cada una de las cuatro dimensiones mencionadas (Van Dijk, 2003; Denzin y Lincoln, 2012; De Villers, 1999; Strauss y Corbin, 2002). El análisis interpretativo contempló: (a) sucesivas lecturas de las entrevistas y cuadernos de campo, (b) análisis preliminares, (c) identificación de experiencias y tensiones, (d) selección de fragmentos discursivos o microtextos, (e) identificación de categorías, (f) elaboración de matrices y (g) teorización interpretativa.

\section{Resultados}

¿Cómo significan la paternidad los trabajadores mineros en un mercado laboral que exacerba su rol productivo-proveedor que demanda más compromiso y cuidado de los(as) hijos(as)? Al respecto constatamos que los estilos de paternidad emergentes en los testimonios se articulan a los mandatos de género tradicionales.

\section{Estilos de paternidad}

En el descanso paso más tiempo con la familia, puedo hacerme cargo de mis niñas; cuando cae día de semana me preocupo cien por ciento de mis niñas, las llevo al colegio, las voy a buscar, hago el almuerzo, hago el aseo, netamente con mis niñas y cuando cae fin de semana, que salgo a pasear, vamos a la playa [HM, 41 años, dos hijas, turno $7 \times 7]$.

Los días de descanso vienen amigos, hacemos asaditos, conversamos o salimos con amigos, compañeros del trabajo que se han venido para el norte. Nunca había tenido 
tanto tiempo para mi familia como el que tengo acá. Por ejemplo, mi chiquitita, la menor, es la que más lo ha disfrutado. Antes no veía a mis hijos mayores [HM, 42 años, cuatro hijas, turno $4 \times 3$ ].

En estos discursos predomina el estilo de paternidad-presente, "señor de la casa", que responde al mandato imaginario de la "resistencia masculina". Luego de los turnos de trabajo continuo, el hombre está dispuesto a sobrepasar sus límites psicofísicos, desplegando una imagen ideal basada en una sociabilidad exacerbada para estar presente durante los descansos en la vida de las hijas, familia y amigos. En el cumplimiento de este mandato se distorsiona el equilibrio entre el orden materno y la presencia paterna. Adicionalmente, la vida cotidiana de la pareja y los(as) hijos(as), propia de los días hábiles, se altera desplazando los hábitos domésticos por actividades de ocio. Esta dinámica dificulta el control logrado por la madre sobre el uso del tiempo y la energía familiar.

Con toda la familia hacemos actividades. Este último cumpleaños de una cuñada, van mis hermanos y todos se disfrazan y también hacemos expediciones en bicicleta. Las últimas dos las organizamos nosotros. Vamos a San Pedro, a Hornito, a Mejillones. Con mis hermanos y mis padres tratamos de consensuar y buscar una fecha, un fin de semana largo [HM, 62 años, cinco hijos, turno $5 \times 2$ y $4 \times 3$ ].

Sin embargo, se han identificado algunas modificaciones de éstos mandatos de paternidad, en los grupos jóvenes, los que se mueven desde una paternidad huidiza o desinteresada, hacia una más responsable. Estos padres desean establecer vínculos cercanos con hijos e hijas, participar en los momentos de recreación y tareas del cuidado (Fuller, 2000; Valdés, 2009). Aunque todavía se encuentran símbolos del condicionamiento del modelo tradicional en sus discursos: "me hago un tiempo" o "si es fin de semana me hago cargo cien por ciento".

Yollego a las doce de la noche, mi hijo está durmiendo. En la mañana se levanta y se va al colegio, yo estoy durmiendo. Tampoco lo veo, lo veo al día siguiente a las tres. Coincidimos cuando comienzo mi descanso, así consigo juntar cuatro días que son para mí para compartir con él. Al final, pasa que no comparto mucho porque él ya ha organizado su vida, tiene su propio mundo, el PlayStation, los amigos, el colegio, entonces me deja de lado [HM, 38 años, un hijo, turno $4 \times 4$ ].

A la vez, los discursos son elocuentes en un sentido contrario, puesto que los trabajadores están insertos en un sistema que los atrapa bajos una alienación económica y laboral (Conti, 2011). Esta es la principal coerción que algunos autores identifican como desmesura laboral (Araujo y Martuccelli, 2012) exacerbada por el sistema de trabajo; y expresada en la sobre exigencia de productividad y en las consecuencias asociadas a los sistemas de turno. Bajo este modelo se retroalimenta una paternidad abdicante, donde el trabajador es superado por el ritmo laboral y familiar, generándose distancia generacional y desencuentros en los intereses de padres e hijos(as). 


\section{Experiencia como padre proveedor}

El lugar del padre como proveedor de la familia se refuerza con el sistema de trabajo de turnos en la minería, y las elevadas remuneraciones que ofrece el rubro. El padre minero debe ser emocionalmente autosuficiente, independiente y capaz de enfrentar la vida sin miramientos, lo cual implica a su vez limitar el contacto social, pero sobre todo inhibe mostrarse débil frente al resto.

Nunca les he preguntado en la familia si valoran mi trabajo, pero para mí sí es un tema de preocupación siempre tener que suministrar los recursos y cubrir lo que ellos requieran [HM, 51 años, dos hijos, turno $4 \times 3$ ].

El discurso ilustra como la masculinidad tradicional se convierte en una armadura rígida que aísla a los hombres entre sí, exigiéndoles vivir en soledad las emociones de postergación, dolor o añoranza (Chávez Plazas y Marchant Espinoza, 2014) Entre los trabajadores entrevistados se reafirma su responsabilidad de jefe de familia, enfocados a satisfacer las expectativas socioculturales, donde las necesidades de los(as) hijos(as) y la(s) familia(s) en general, son lo central:

Nunca me he preguntado si valoran o no mi trabajo, pero a mí nunca me gustaría que les faltara nada a mis hijos [HM, 42 años, dos hijos, turno $4 \times 3$ y $5 \times 2$ ].

Los hombres valoran el trabajo que sostiene su identidad masculina, respondiendo a un mandato que los conserve como padre proveedor $\mathrm{y}$, a la vez, en la jefatura familiar (Olavarría, 2004). En los grupos estudiados el mandato es: ser trabajador, reconocido como padre-jefe y mantenerse como proveedores, que les permita - a pesar de los costos, exigencias y riesgos - financiar a la familia en sus necesidades y garantizar un futuro imaginado. La idea de perder estas posiciones, exacerbadas por las fluctuaciones laborales y económicas que muestra la industria minera a nivel global en la última década, los empuja a una sobre exigencia extrema de tiempo y de energía psicofísica orientada al trabajo.

En el caso de la gran minería del cobre en Chile, el lugar del padre proveedor se ve exagerado en cuanto al poder adquisitivo del "sueldo minero", despojándolo de otros atributos como el ejercicio de la autoridad o la jefatura de hogar, pues aparece sobrevalorada la capacidad económica y erosionada su autoridad en la familia a raíz de su tiempo de ausencia y la presencia visible de la madre de este lugar de poder frente a los hijos e hijas (Lahire, 2002; Pavéz y Hernández, 2014).

Ahora le pasamos [a los hijos] la tarjeta de crédito para que compren lo que necesitan, porque ya son independientes. Antes la mamá les compraba todo, pero ahora ya eligen sus temas. Ellos son responsables en ese sentido y tenemos confianza en que pueden manejar el dinero [HM, 41 años, dos hijos, turno 7×7].

En el lugar de proveedor, el padre asume que los hijos poseen autocontrol en los gastos y les otorga libertad para que sean "independientes" y puedan cubrir sus 
necesidades. Estas iniciativas podrían favorecer el estilo de paternidad delegada y desinteresada, reafirmando la imagen social de poder adquisitivo del hombre. Asimismo, distanciar el vínculo padre-hijo(a), en el que destacan dos dimensiones contrarias: (a) confianza y madurez en la relación entre ambos o (b) desafección paterna, expresada en una baja participación en el desarrollo de los gustos o necesidades específicas de los(as) hijos(as), puesto que al compartir estas actividades, podría fortalecer la comunicación, complicidad y una mayor cercanía en el vínculo padre e hijo(a).

Cuando los niños empiezan la universidad ¡te pones más pobre!, a pesar que trabajaste 15 o 20 años haciéndote una base económica. Conocí a colegas que tenían dos y tres hijos estudiando odontología, medicina, ingeniería. ¡Entonces los sueldos no cubrían semejante gasto! A pesar de que somos ingenieros civiles con postgrados, no te da el sueldo, así que empezaban a endeudarse hipotecando la casa, pidiendo créditos a los bancos. Por eso nos vinimos al norte. Eso permitió que a mí me finiquitaran en el sur y buscar nuevos rumbos en la minería [HM, 48 años, cuatro hijos, turno $5 \times 2$ y $4 \times 3$ ].

En esta posición de género, el padre se ubica en un lugar activo como proveedor y responsable. Desde allí debe operar como garante del futuro profesional de sus hijos(as), planificar su estrategia laboral y su futuro en relación a la posibilidad de financiar la educación superior. Desde esa perspectiva, se refuerza el modelo tradicional de familia, donde el peso económico lo enfrentan los hombres adultos, asumiendo los altos costos de financiamiento en educación.

El padre-trabajador, al asumir el lugar de único proveedor, posterga su bienestar físico y psicológico, con escasas condiciones de negociación al interior de la familia y menos aún en el espacio laboral. En este modelo socio relacional se generan tensiones padre-familia-trabajo, ya que se retarda la independencia económica de los hijos, a la vez se agudiza la dependencia económica del trabajador respecto al sueldo minero, pues de ello deriva el bienestar y calidad de vida de la familia y la movilidad social, que permite el financiamiento de los estudios, en una sociedad donde el rol del Estado en este ámbito ha sido fundamentalmente subsidiario.

Con mis hijos, conversamos bastante la responsabilidad de cada uno. Mi responsabilidad es trabajar, traer recursos para la casa para que mi familia esté bien. La responsabilidad de ellos es estudiar. Yo siempre les digo que las notas que se saquen son el sueldo que se van a ganar el día de mañana [HM, 62 años, cinco hijos, turno $5 \times 2$ y $4 \times 3$ ].

En relación a la segunda pregunta de investigación - ¿Cómo enfrentan estas nuevas tensiones de género los trabajadores, producto de un modelo que agudiza la dicotomía entre paternidad-familia-trabajo? - se analizaron las siguientes categorías: (1) posición de género: prácticas laborales y distribución de tareas; y (2) tensiones entre los turnos en la mina y la familia. 


\section{Posición de género: prácticas laborales y distribución de tareas}

Mi esposa se preocupa de mi hija pequeña, del colegio, dejarla, buscarla. Hace las cosas necesarias para las niñas chicas; mi hijo estudia en la universidad. Ella, mi esposa, es profesional pero no trabaja, se ha dedicado siempre a los niños, sale de compras al mall. Yo trabajo toda mi vida en la mina y me encargo de llevar el dinero a casa [HM, 62 años, cinco hijos, turno $5 \times 2$ y $4 \times 3$ ].

Mis niñas solamente juegan. Mi señora cocina, está a cargo de los niños, llevarlos a la escuela. También está a cargo de la casa, haciendo la limpieza, ropa, cocina, trabaja junto con nuestra nana. Los fines de semana yo estoy aquí, también la apoyo en cocinar y ordenar las cosas básicas y cuidar los niños [HM, 30 años, dos hijas, turno $4 \times 3$ y 5×2].

En los discursos se observa la vigencia del modelo tradicional de género de separación de esferas masculinas y femeninas, con una distribución de tareas basada en la distinción entre el ámbito público/privado. La mujer se desarrolla como cuidadora de la familia y el hombre como proveedor exclusivo. En este modelo de relaciones predomina el estilo cultural-familiar tradicional, es reforzado por el sistema productivo minero, debido a las dificultades para negociar la gestión de la vida privada y compatibilizar las demandas laborales y familiares, por lo tanto parece inmune a las transformaciones de género ocurridas en la sociedad chilena contemporánea.

Este modelo acentuado en las regiones mineras contribuye a la menor participación laboral del sector femenino, quedando las mujeres atrapadas en este estilo de familia, sin autonomía económica y con una alta carga de responsabilidades domésticas, asumiendo los roles de madre y padre (Salinas et al., 2010).

\section{Tensiones entre los turnos en la mina y la familia}

Yo tengo los tres hijos mayores, siempre ellos me decían que ni pensara que ellos iban a estudiar ingeniería, porque para ellos significaba no estar nunca en la casa, no compartir con los hijos. Yo empecé en los años 90, se usaba un "viper" que te lo colocabas en el cinturón y por ahí te llegaba un mensaje de la casa. [HM, 62 años, cinco hijos, turno $5 \times 2$ y $4 \times 3]$.

Me he perdido de muchas navidades, años nuevos, fiestas patrias, los cumpleaños de mi hijo, de mi señora, los míos los propios. Fechas importantes que me ha tocado trabajar. Tenemos que hacernos a la idea. Si me preguntaran cuál fiesta me gustaría pasar en casa, diría navidad. Es más familiar, el estar con el hijo, ver que abra los regalos, estar con la familia, estar con la esposa es lo mejor [HM, 38 años, un hijo, turno $4 \times 4$ ].

La dinámica familiar generada por los sistemas de turno, reproduce los valores normativos que frenan los procesos de democratización de la vida familiar y fortalecen la división sexual del trabajo en la familia, la sociedad y las empresas. Este tipo de inserción masculina impide el ejercicio de una paternidad que afirme las relaciones de 
filiación y también la conyugalidad, con interacciones afectivo-familiares menos invadidas por la colonización que el trabajo ejerce en la familia.

En la actualidad, con mi hija pequeña, comparto lo que no compartí con mis hijos mayores, por los turnos. A veces jugamos un rato, la veo hacer sus tareas, a veces le ayudo. Siempre estoy, vengo todos los días a la casa con ella y resuelvo algunos conflictos porque sé lo que pasó en el colegio y distintas cosas de la vida cotidiana que allá en la mina del sur, con sus hermanos, yo no llegaba por mis turnos [HM, 30 años, dos hijas, turno $4 \times 3$ y $5 \times 2$ ].

En los discursos destaca el esfuerzo del padre por estar presente y hacerse parte de la rutina familiar en el cuidado de las hijas, aún con el cansancio laboral acumulado, situación que se ha encontrado en familias y parejas más jóvenes, buscando el ajuste entre la vida laboral y familiar. Cuando no hay rigidez en los sistemas de turno se flexibilizan los tiempos destinados a los hijos, en cambio cuando los padres están sometidos a estos sistemas de entrada y salida de la casa se naturaliza en los mismos hijos las ausencias de los padres, desplazando sus preocupaciones y decisiones solo con la madre.

Cuando mi hijo era más chiquitito, tenía tres años, me salía a dejar al bus y se ponía a llorar. Entonces me daba mucha pena porque no me quería ir. Hablábamos, que me echaba de menos, que me regresara a casa - vente papito, después te vas a trabajar de nuevo. Cosas de niño que pedía, pero que son imposibles. Pero ahora que él está más grande yo le digo - ya hijo, me voy a ir, ¿me vas a ir a dejar? -, me mira y no deja de hacer lo que está haciendo, y ¡chao papá! me dice que te vaya bien! [HM, 38 años, un hijo, turno $4 \times 4$ ]

En los más jóvenes se intenta modificar las experiencias que tuvieron siendo hijos de padres mineros, lo que muestra más reflexividad en el ejercicio de la paternidad. Sin embargo, el trabajador igualmente se presiona por restringir sus emociones negativas, lo que a la larga deriva en su menor bienestar.

Mi papá fue minero, trabajó toda su vida en Codelco [Corporación Nacional del Cobre]. Entonces mi papá cualquier cosa que le pasara en el trabajo llegaba enojado a la casa discutiéndolo todo. Yo trato de no hacerlo, pero claro que se me nota cuando ando preocupado [HM, 30 años, dos hijas, turno $4 \times 3]{ }^{4}$

En otros discursos, también constatamos, que ante las continuas separaciones de los(as) hijos(as), se generan sentimientos de tristeza, tanto para el padre como para el hijo(a), que con el tiempo y sus reiteraciones, se expresa en el apego o desapego que atraviesa la dinámica familiar minera, volviéndose cotidiana la ausencia y marcando un estilo de relación padre-hijos(as). Este sistema refuerza un conflicto que no se resuelve mientras el trabajador y su familia han asimilado el sistema de turnos, como un régimen del que no pueden escapar.

4 Días trabajados por días de descanso $4 \times 4,4 \times 3,5 \times 3,8 \times 6,5 \times 5,6 \times 4,8 \times 8,9 \times 7,10 \times 10,15 \times 15$. 


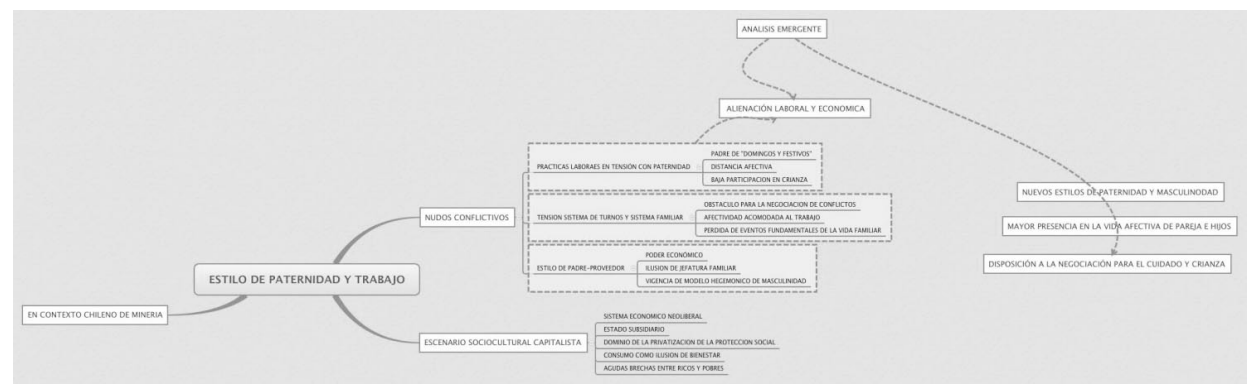

Figura 1 Mapa modelo de análisis emergente

Fuente: elaboración propia.

\section{Discusión}

Como se sintetiza (resultados) en el mapa de análisis emergente, el estilo de paternidad del grupo de trabajadores estudiados se articula en torno a tres subcategorías: (a) vigencia de un modelo tradicional de género reforzado por la dinámica productiva; (b) exacerbación laboral, que empuja a la subordinación del hombre al trabajo en desmedro de otros aspectos de su vida; y (c) exacerbación económica asociada al poder adquisitivo y al control de los recursos, que estimula la ilusión del lugar del padre como cabeza de familia.

Al desagrupar estas problemáticas, es posible comprender desde la perspectiva teórica, cómo desde la subjetividad los hombres vinculados a la minería significan su lugar en la familia y la paternidad. Resultados que se asemejan a estudios realizados en Australia (Pini y Mayes, 2012; Pini, Mayes y Boyer, 2013) y en Inglaterra (Hubbard, 1999), resguardando las distinciones y particularidades socioeconómicas y de desarrollo cultural. Para esto, es necesario situar al hombre-padre-trabajador en el escenario global y enfocar la mirada hacia lo local, aporte que realiza este estudio. Desde esa posición, se observan las transformaciones culturales ocurridas desde finales del siglo XX en el mundo occidental, influidas por la posmodernidad, como el paulatino proceso de debilitamiento de las instituciones totales (Estado, Iglesia, familia y escuela) y sus figuras de representación (Derrida, 1997; Mouffe, 2007).

En este proceso de mutaciones socioculturales, los símbolos con poder de mandatos fijos e incuestionables, quedan desnudos ante la mirada social, mostrando su resquebrajamiento. La transformación cultural y en el orden normativo, ha contribuido a modificar el sistema de jerarquías en las relaciones de género, mostrando cambios en ciertas dimensiones, pero a su vez tensiones por los modos de inserción laboral de los trabajadores, donde se refuerzan los patrones tradicionales, descritos en los análisis de este artículo.

Una de las consecuencias es la progresiva desvalorización y desacreditación de la figura del padre en la escena familiar, que se acrecienta dada las altas exigencias de flexibilidad (sistemas de subcontratación y de turnos) que impone el 
mercado laboral en el contexto neoliberal imperante (Olavarría, 2004; Connell y Artigas, 2003).

A diferencia de los estudios revisados, otro aporte de esta investigación es visibilizar la centralidad del papel de proveedores de los trabajadores de la minería, el que se singulariza por el manejo de amplios recursos acompañados por la fragmentación de los tiempos en la mina y la casa. Así a nivel global está en un constante movimiento ambivalente entre: cuerpo vendido-perdido, gastado, cansado. Luego en esta satisfacción (placer) con lo obtenido (en lo económico), lo que queda es un: cuerpo-recuperado, perdido, como cosa-mercancía (Asselborn, 2015). Así en esta dinámica circular la inhibición emocional se expresa en un juego entre control y libertad, dejando un vacío, hasta ahora escasamente documentado, en el hombre-trabajador-padre generado por el "sacrificio" laboral.

\section{Conclusiones}

A partir de los hallazgos concluimos que:

1) Existe una diversidad de obstáculos que, si bien se recogen en una región del norte de Chile, se encuentran en intensidad similar en otras culturas mineras, como ya señalamos, de Australia, Inglaterra y Canadá, pese a su condición de mayor desarrollo socioeconómico.

2) La experiencia de estas familias mineras y de sus estilos de paternidad, resulta útil para comprender avances y resistencias al cambio en la subjetividad masculina y femenina en torno al campo laboral. En estos procesos complejos se expresan las identidades de los hombres del mundo contemporáneo occidental, sometidos a los sistemas laborales, donde prima la precarización de estas relaciones y el aumento global de la desigualdad.

3) La alta flexibilidad se conjuga con el prestigio de mantener el estatus de proveedor principal, recreando el viejo modelo patriarcal que perpetúa las inequidades a nivel familiar y social en el siglo XXI. No obstante, encontramos algunas fisuras auspiciosas en este modelo, sobre todo en los padres-trabajadores más jóvenes, que dan cuenta de las necesidades y beneficios de una mayor presencia en la familia en particular cuando de actividades recreativas y de cuidado se trata. Estos nuevos estilos de ser hombres y padres, movilizados por el empoderamiento femenino y por los cambios con respecto de la infancia, favorecen la emergencia de transformaciones laborales.

4) La gestión de estas transformaciones, implica recuperar para la organización de los trabajadores, derechos a una relación laboral que incluya a los sujetos en un sentido integral, donde la calidad de vida subjetiva, emocional, familiar y laboral sea central, promoviendo una paternidad activa y responsable. Desde una perspectiva casteliana, sería necesario reactivar los vínculos de afiliación del hombre-trabajador moderno con sus redes de sociabilidad familiares protectoras, ampliando las tramas colectivas. 
Esta propuesta no constituye un ajuste de perspectiva, sino que en las políticas públicas es necesario poner énfasis en el individuo como sujeto biopsicosocial, sin desdenar en estas preocupaciones los tiempos de trabajo. En síntesis, para alcanzar cambios que modifiquen las relaciones de género y el lugar periférico del padre en la familia minera, consiste en establecer un nuevo trato entre el Estado, sector privado y ciudadanía hacia una transformación cultural que aborde el cansancio del hombre-padre-trabajador, orientado a: (a) recuperar los derechos familiares y sociales de las personas; (b) de-construir los roles de género asignados desde los modelos de jerarquías autoritarias y androcéntricas; (c) los sistemas productivos que incluyan a hombres y mujeres en su integralidad emocional, afectiva, productiva y reproductiva; y (d) promover una responsabilidad compartida entre empresa-familia y trabajador, orientada a preservar la salud mental y el bienestar global de la familia, del trabajador $\mathrm{y}$, finalmente, de la vida social.

\section{Limitaciones}

Se recomienda ampliar en esta línea investigativa a otros sujetos participantes, incluyendo la visión de las parejas e hijos(as) de trabajadores con el objetivo de explorar en profundidad la relación padres e hijos(as) y de las parejas. Así también se recomienda, estudiar las implicancias de la posición socioeconómica de los trabajadores mineros a nivel local y nacional, en relación a sus interacciones de género y laboral respecto a otros rubros de la economía.

\section{Bibliografía}

Abarca, Nureya, y Margarita Errázuriz (2007), “Propuestas para la conciliación trabajo y familia", en Gobierno de Chile y Pontificia Universidad Católica, Camino al Bicentenario. Propuestas para Chile, Santiago de Chile, PUC, disponible en: http://politicaspublicas.uc.cl/wp-content/uploads/2015/02/propuestas-para-la-conci liacion-trabajo-y-familia.pdf (última consulta en abril 2017).

Aguayo, Francisco, y Marcos Nascimento (orgs.) (2016), “Dos décadas de estudios de hombres y masculinidades en América Latina: avances y desafíos", Sexualidad, Salud y Sociedad (Rio de Janeiro), 22, pp. 207-220, disponible en: https://dx.doi.org/10.1590/1984-6487.sess.2016.22.09.a (última consulta en enero 2017).

Araujo, Kathya, y Danilo Martuccelli (2012), Desafíos Comunes. Retrato de la Sociedad Chilena y Sus Individuos, tomo II: Serie Individuo y Ciencias Sociales, Santiago de Chile, Lom Ediciones.

Asselborn, Carlos (2015), “Economía, ética y estética: ¿Qué hace el capitalismo con el cuerpo que somos?, Economía y Sociedad, XIX (32), pp. 55-70.

Batthyany, Karina (2009), "Autonomía de las mujeres y resistencias a la división sexual del trabajo al interior de las familias", en Seminario Regional "Las Familias Latinoamericanas Interrogadas. Hacia la Articulación del Diagnóstico, la Legislación y las Políticas", Santiago de Chile, Cepal. 
Carrasco, Celina, y Patricia Vega (2011), Una Aproximación a las Condiciones de Trabajo en la Gran Minería de Altura, Cuaderno de Investigación n.ํㅜ 40, Santiago de Chile, Gobierno de Chile, Dirección del Trabajo, Departamento de Estudios, disponible en: http://www.dt.gob.cl/m/1620/articles-100032_recurso_1.pdf (última consulta en marzo 2017).

Casen - Encuesta de Caracterización Económica (2013), disponible en: http://www.ministeriodesarrollosocial.gob.cl/basededatoscasen.php (última consulta en mayo 2017).

Castel, Robert (2012), El Ascenso de las Incertidumbres. Trabajo, Protecciones, Estatutos del Individuo, Buenos Aires, Fondo de Cultura Económica (1. a edición).

Castelain-Meunier, Christine (2005), “Les métamorphoses du masculin”, Revue Française de Sociologie, 48 (2), pp. 423-425, disponible en: http://www.jstor.org/stable/40217674 (última consulta en abril 2017).

Cepal - Comisión Económica para América Latina y el Caribe (2011), Panorama Social de América Latina, Santiago de Chile, Cepal.

Chávez Plazas, Yuri, y Juan Paulo Marchant Espinoza (2014), “Nuevas masculinidades en desplazamiento: construcciones sociales y culturales del significado de ser hombre. Una mirada desde Chile y Colombia", Tabula Rasa, 21, pp. 287-303, disponible en: http://www.scielo.org.co/scielo.php?script=sci_arttext\&pid=S1794-24892014000200 015\&lng=en\&tlng=es (última consulta en mayo 2017).

Connell, Raewyn (2005), Masculinities, Sydney, Allen \& Unwin (2.ㄹ edición).

Connell, Raewyn, y Irene Artigas (2003), Masculinidades, México, DF, Universidad Nacional Autónoma de México, Programa Universitario de Estudios de Género.

Conti, Romina (2011), “La desalineación estética en Schiller y Marcuse: un retorno sobre el problema de la racionalidad mutilada", Tópicos, 21, disponible en, http://www.scielo.org.ar/scielo.php?script=sci_arttext\&pid=S1666-485X2011000100 003 (última consulta en febrero 2017).

Denzin, Norman, y Yvonna Lincoln (coords.) (2012), El Campo de la Investigación Cualitativa. Manual de Investigación Cualitativa, Barcelona, Gedisa.

Derrida, Jacques (1997), Fuerza de Ley. El Fundamento Místico de la Autoridad, Madrid, Tecnos.

De Villers, Guy (1999), “La historia de vida como método clínico”, Revista Proposiciones, 29, pp. 103-114.

Figueroa, Juan Guillermo (2014), Políticas Públicas y la Experiencia de Ser Hombre. Paternidad, Espacios Laborales, Salud y Educación, México, DF, El Colegio de México.

Figueroa, Juan, Lucero Jiménez, y Olivia Tena (2006), Ser Padres, Esposos e Hijos. Prácticas y Valoraciones de Varones Mexicanos, México, DF, El Colegio de México.

Flores, Angeles, y Olivia Tena (2014), “Maternalism and Latin American Feminist discourses on caregiving work: a fabric in tension", Icons Social Science Journal, 50, pp. 27-42.

Fuller, Norma (2000), “Conclusiones”, en N. J. Fuller (org.), Paternidades en América Latina, Lima, Pontificia Universidad Católica del Perú, Fondo Editorial, pp. 387-394. 
Gray, Ben (2010), “Emotional labour, gender and professional stereotypes of emotional and physical contact, and personal perspectives on the emotional labour of nursing", Journal of Gender Studies, 19 (4), pp. 349-360.

Hubbard, Phil (1999), Sex and the City. Geographies of Prostitution in the Urban West, Londres, Ashgate.

Jackson, Stevi (1996), "Heterosexuality and feminist theory", en D. Richardson (org.), Theorising Heterosexuality, Buckingham, Open University Press, pp. 21-38.

Kaufmann, Jean-Claude (1993), Sociologie du Couple, París, Presses Universitaires de France.

Lahire, Bernard (2002), O Homem Plural. Os Determinantes da Ação, Petrópolis, Vozes.

Leiva, Sandra, y Andrea Comelin (2015), “Conciliación entre la vida familiar y laboral: evaluación del programa Iguala en una empresa minera en la región de Tarapacá", Polis (Santiago), 14 (42), pp. 345-368.

Lindberg, Laura, Klaus Kost, y Isaac Maddow-Zimet (2017), “El papel de las intenciones embarazo de los hombres en la participación del padre", Fam Relat, 79, pp. 44-59.

March, Evita, Rolf Van Dijk, y Alina Hernández (2015), “Current prescriptions of men and women in differing occupational gender roles", Journal of Gender Studies, 30, pp. 1-12.

Meller, Patricio (2013), La Viga Maestra y el Sueldo de Chile, Mirando el Futuro con los Ojos del Cobre, Santiago de Chile, Uqbar Ediciones.

Mouffe, Chantal (2007), En Torno a lo Político, Buenos Aires, Fondo de Cultura Económica.

Núñez, Guillermo (2016), “Los estudios de género de los hombres y las masculinidades: ¿qué son y qué estudian?", Revista Culturales, época II, IV (1), pp. 9-31.

Olavarría, José (2000), “Ser padre en Santiago de Chile”, en N. Fuller (org.), Paternidades en América Latina, Lima, Pontificia Universidad Católica del Perú, Fondo Editorial, pp. 129-173.

Olavarría, José (2004), “Masculinidades, poderes y vulnerabilidades”, en Flacso (org.), Los Nuevos Escenarios Internacionales, Santiago, Flacso, pp. 227-244.

Pavéz, Jorge, y Gerardo Hernández (2014), “Regímenes de trabajo, relaciones laborales y masculinidades en la gran minería del cobre (norte de Chile)", en Ximena Valdés, Loreto Rebolledo y Jorge Pavéz (orgs.), Trabajos y Familias en el Neoliberalismo, Hombres y Mujeres en Faenas de la Uva, el Salmón y el Cobre, Santiago de Chile, Lom Ediciones, pp. 169-272.

Pini, Barbara, y Robyn Mayes (2012), "Gender, emotions and fly-in fly-out work”, Australian Journal of Social Issues, 47 (1), pp. 71-86.

Pini, Barbara, Robyn Mayes, y Kate Boyer (2013), “'Scary' heterosexualities in a rural Australian mining town", Journal of Rural Studies, 32, pp. 168-176.

Salinas, Paulina, Claudia Reyes, Gianni Romaní, y Marcela Ziede (2010), “Mercado laboral femenino: un estudio empírico desde la perspectiva de la demanda en la región minera de Antofagasta, Chile", Innovar - Revista de Ciencias Administrativas y Sociales, 20 (38), pp. 125-140.

Salinas, Paulina, Jaime Barrientos, y Pablo Rojas (2012), “Discursos sobre la discriminación de género en los trabajadores mineros del Norte de Chile", Atenea, 505, pp. 139-158. 
Salinas, Paulina, y Gianni Romaní (2016), “Hegemonía masculina, freno en equipos mixtos en la minería chilena", Revista Mexicana de Sociología, 78 (3), pp. 469-496.

Secretaría Regional de Minería (2015), “Balance 2019 en minería encabezado por el ministro Prokurica", disponible en: http://www.minmineria.gob.cl/ (última consulta en marzo 2017).

Sheng, Xiaoming (2013), “Gender and habitus: parental involvement in students' subject choices", China Journal of Gender Studies, 24 (2), pp. 227-238.

Silva, Jimena, y Jaime Barrientos (2008), “Sexual scripts about seduction, eroticism and sexual encounters in the north of Chile", Feminist Studies Magazine, 16 (2), pp. 539-556.

Strauss, Anselm, y Juliet Corbin (2002), Bases de la Investigación Cualitativa, Facultad de Infermería de la Universidad de Antioquia, Contus Ediciones.

Valdés, Ximena (2007), La Vida en Común. Familia y Vida Privada en Chile y el Medio Rural en la Segunda Mitad del Siglo XX. Santiago de Chile, Lom Ediciones.

Valdés, Ximena (2009), “El lugar que habita el padre en Chile contemporáneo: estudio de las representaciones sobre la paternidad en distintos grupos sociales", Polis, 8 (23), pp. 385-410.

Van Dijk, Teun (2003), Ideología y Discurso, Barcelona, Ariel.

Wainerman, Catalina (2007), “Conyugalidad y paternidad ¿Una revolución estancada?”, en María Alicia Gutiérrez, Género, Familias y Trabajo. Rupturas y Continuidades. Desafíos para la Investigación Política, Buenos Aires, Clacso, Consejo Latinoamericano de Ciencias Sociales.

Ward (2015), “The chameleonisation of masculinity: Jimmy's multiple performances of a working-class self", MCS - Masculinities and Social Change, 4 (3), pp. 215-240.

Jimena Silva. IR fondecyt 1180079. Doctora en Antropología, professora titular, Escuela de Psicología, Facultad de Humanidades, Universidad Católica del Norte, Antofagasta, Chile.E-mail: jsilva@ucn.cl.

Paulina Salinas. IR fondecyt 1180016. Doctora en Ciencias Sociales, professora titular, Escuela de Periodismo, Facultad de Humanidades, Universidad Católica del Norte, Antofagasta, Chile. E-mail: psalinas@ucn.cl

Receção: 18 de janeiro de 2018 Aprovação: 24 de maio de 2018 